\title{
Growth suppression of thyroid cancer cells by adenylcyclase activator
}

\author{
YUKIKO YANO $^{1,2}$, HIROSHI KAMMA ${ }^{3}$, HIROFUMI MATSUMOTO ${ }^{3}$, \\ MASACHIKA FUJIWARA ${ }^{3}$, HIROKO BANDO ${ }^{1}$, HISATO HARA ${ }^{1}$, \\ TOHRU YASHIRO ${ }^{1}$, EI UENO ${ }^{1}$, KOICHI ITO ${ }^{2}$ and KAZUHIKO UCHIDA ${ }^{4}$ \\ ${ }^{1}$ Institute of Clinical Medicine, University of Tsukuba, Ibaraki 305-8577; ${ }^{2}$ Ito Hospital, \\ Tokyo 150-8308; ${ }^{3}$ Department of Pathology, Kyorin University School of Medicine, \\ Tokyo 181-8611; ${ }^{4}$ Graduate School of Comprehensive Human Sciences, Tsukuba Industrial \\ Liaison and Cooperative Research Center, University of Tsukuba, Ibaraki 150-8308, Japan
}

Received March 23, 2007; Accepted April 30, 2007

\begin{abstract}
Thyroid stimulating hormone (TSH) is known to increase intracytoplasmic cyclic adenosine monophosphate (cAMP) and to regulate the growth of normal follicular cells. The aim of this study was to explore the role of the cAMPmediated signaling pathway stimulated by TSH as a cell growth modulator in human thyroid cancer cells. One papillary thyroid cancer cell line, K1 cells and two anaplastic thyroid cancer cell lines, TTA1 and TTA2 cells were treated with forskolin, which directly activates adenyl cyclase to raise the level of intracellular cAMP. Forskolin suppressed thyroid cancer cell proliferations, especially in $\mathrm{K} 1$ cells, in a dosedependent manner and induced growth arrest at the G0/G1 phase of the cell cycle. We also examined the expression of mitogen activated protein kinase (MAPK) after the forskolin treatment. Forskolin reduced the activation of growth factor induced MAPK activity. In conclusion, we demonstrated that forskolin was involved in G1 arrest and MAPK activation in $\mathrm{K} 1$ thyroid cancer cells. Our study suggests that the TSH signal mediated by cAMP acts as a negative regulator in thyroid cancer cells, unlike that in normal follicular cells.
\end{abstract}

\section{Introduction}

Thyroid stimulating hormone (TSH), which causes cyclic adenosine monophosphate (cAMP) formation, is involved in

Correspondence to: Dr Hiroshi Kamma, Department of Pathology, Kyorin University School of Medicine, 6-20-2 Shinkawa, Mitaka, Tokyo 181-8611, Japan

E-mail: hkamma@kyorin-u.ac.jp

Abbreviations: cAMP, cyclic adenosine monophosphate; IGF, insulin-like growth factor; HGF, hepatocyte growth factor; MAPK, mitogen activated protein kinase; TSH, thyroid stimulating hormone; TSHR, TSH receptor

Key words: thyroid cancer, cAMP, MAPK, forskolin, cell growth thyroid organogenesis, cell differentiation, iodide uptake and triiodothyronine secretion $(1,2)$. The stimulated TSH receptor activates adenyl cyclase via a Gs protein at higher concentrations of phospholipase $\mathrm{C}$, leading to increased intracellular cAMP which mediates multiple signaling pathways. Intracellular concentrations of cAMP act to maintain the phenotype of differentiation of thyroid follicular cells, the level of hormonal activity, and cell growth (1). The same effect as TSH stimulation is achieved by forskolin. Forskolin, which is extracted from vegetation, is a universal activator of adenyl cyclase (3) and induces the accumulation of cAMP in thyroid cells (4). Forskolin elevates intracellular cAMP or a cAMP analogue which activates the cAMPmediated intracellular signaling pathway of TSH (1).

Continuous stimulation of the TSH receptor (TSHR) increases the mitotic activity of follicular cells and the number of follicles per thyroid gland (5), as clinically observed in Graves' disease. Experimentally, TSH stimulates proliferation of thyroid follicular cells in rat and dog $(1,6)$. However, TSH does not affect follicular cell proliferation on its own. It requires a high concentration of insulin, in human thyroid cells, or some growth factors (1). The in vitro effects of TSH on thyroid cell growth may be different depending on race and/or experimental design. Moreover, the effects of TSH on the cell growth seem to clinically differ among thyroid diseases. For the development and progression of thyroid tumors, it has been generally thought that TSH stimulation is necessary (7). It has also been reported that the TSHR was observed at the basal cell surface in most papillary thyroid cancers, but not in anaplastic thyroid cancers, indicating that thyroid cancers retain the ability to respond to TSH (8).

The relationship between the cAMP signaling pathway and mitogen activated protein kinase (MAPK) signal transduction induced by various growth factors is still unknown in human thyroid cancer. It was previously reported that TSH activated MAPK in rat thyroid cells (9); however, others have reported that there is no synergy between cAMP and MAPK cascades in dog thyrocytes (10). The proliferation of thyroid cancer cells has been reported to be modulated by various cytokines and growth factors (11). Various growth factors 
bind to their specific transmembranous tyrosine kinase receptors that then activate the MAPK, which are intracellular signaling molecules involved in diverse array of cellular responses including cell growth and differentiation (12). MAPK activation causing signaling cascades downstream of growth factor receptors has been implicated in the malignant transformation of mammalian cells $(12,13)$. The metastin receptor is overexpressed in papillary thyroid cancer and it activates MAPK in thyroid cancer cells (14). These observations suggest a link between thyroid cancer growth and the MAPK signaling pathway.

The aim of this study was to explore the role of the cAMP-mediated signaling pathway of TSH stimulation as a modulator of cell growth in thyroid cancer cells. We examined the effects of elevated levels of cAMP, produced by forskolin stimulation, on the cell proliferation of three thyroid cancer cell lines. We further investigated the interaction of the cAMP and MAPK-mediated signaling pathways. Forskolin inhibited cell growth, induced G1 arrest in human thyroid cancer cells, and reduced phosphorylation of MAPK. Our data indicate that the cAMP pathway functions as a negative regulator in thyroid cancer cells, unlike its stimulatory effects in normal thyroid cells, and suggests that this effect is a part of the MAPK signaling pathway.

\section{Materials and methods}

Cell lines and culture. Three human thyroid cancer cell lines, K1 (papillary thyroid cancer, provided by the European Collection of Cell Culture, Wiltshire, UK) (15) and TTA1 and TTA2 (anaplastic thyroid cancers, provided by Tsukuba University, Ibaraki, Japan) (16) were used in this study. K1 cells were cultured in DMEM/Ham F-12 medium (Gibco Life Technologies, Millipore, NY) (1:1, by volume) supplemented with $5 \%$ fetal bovine serum (FBS), $1 \%$ ITS $^{+}$(final concentrations were $2 \%$ Ultroser G, $2 \mathrm{mM} / 1$ glutamine, $5 \mu \mathrm{g} / \mathrm{ml}$ transferrin, $5 \mathrm{ng} / \mathrm{ml}$ selenium, $5 \mathrm{ng} / \mathrm{ml}$ linoleic acid) (Sigma, St. Louis, MO), $50 \mathrm{U} / \mathrm{ml}$ penicillin and $100 \mu \mathrm{g} / \mathrm{ml}$ streptomycin at $37^{\circ} \mathrm{C}$ and $5 \% \mathrm{CO}_{2}$. TTA1 and TTA2 cells were cultured in DMEM supplemented with $10 \%$ FBS, $50 \mathrm{U} / \mathrm{ml}$ penicillin and $100 \mu \mathrm{g} / \mathrm{ml}$ streptomycin. All cells were cultured in medium supplemented with 5\% FBS for $24 \mathrm{~h}$ before studies. Human thyroid tissues were obtained from surgically removed thyroid tumors with institutional review approval.

$R N A$ extraction and reverse transcription -PCR. RNA was extracted from collected cells using the Isogen reagent (Nippon Gene, Tokyo, Japan). The RNA (1 $\mu \mathrm{g})$ from each cell line was used for cDNA production using an RNA PCR kit (Takara, Kyoto, Japan) with random nonamers in a total volume of $20 \mu \mathrm{l}$. The RNA obtained from human thyroid tissues were examined as a control. Aliquots $(1 \mu 1)$ of the reverse transcription products were amplified in $20 \mu \mathrm{l}$ of reaction buffer containing $0.2 \mu \mathrm{M}$ of each primer, $1 \mathrm{mM}$ of dNTPs and 5 units Taq DNA polymerase (Promega, Madison, WI). The previously described specific primers for the TSH receptor (17) were used. The amplified products were electrophoresed on $5 \%$ non-denaturing polyacrylamide gels in $0.5 \mathrm{X}$ Tris-borate EDTA buffer, stained with SYBR Green I, and scanned with fluorimager.

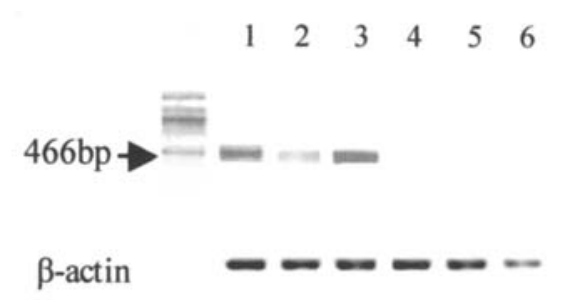

Figure 1. RT-PCR bands (466 bp) showing THSR expression are seen in thyroid tissues but not in thyroid cancer cell lines. The lanes are: human thyroid tissues (1: normal thyroid; 2 and 3: papillary thyroid cancer) as controls, 4: TTA1 and 5: TTA2 anaplastic thyroid cancer cells, and 6: K1 papillary thyroid cancer cells.

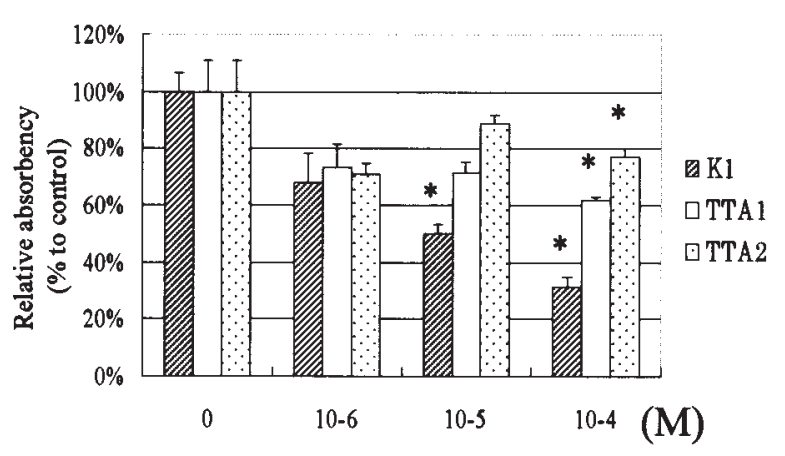

Figure 2. Thyroid cancer cell growth was inhibited by forskolin. K1, TTA1 and TTA2 cells were cultured in DMEM medium supplemented with $2.5 \%$ FBS and various concentrations of forskolin $\left(0-10^{-4} \mathrm{M}\right)$. After a 2-day incubation, a WST-1 cell proliferation assay was performed. Data are expressed as mean $\pm \mathrm{SD}$ of three independent experiments with triplet cultures in each experiment. All absorbencies are expressed as a percentage of the untreated control cultures. ${ }^{*} \mathrm{p}<0.05$ vs. control.

Cell growth assay. Cells were seeded in 96-well microplates at a concentration of 5000 cells per well in DMEM supplemented with $2.5 \%$ FBS and cultured for $24 \mathrm{~h}$. The cells were then incubated for an additional $48 \mathrm{~h}$ in medium containing forskolin (Sigma), insulin-like growth factor-1 (IGF-1) (PeproTech, Rocky Hill, NJ) and hepatocyte growth factor (HGF) (Techne Corporation, Minneapolis, MN). In this study forskolin was used to increase cytoplasmic cAMP. IGF-1 and HGF were selected to activate tyrosine receptor kinase. After 2 days of culture, cell proliferation of the thyroid cancer cells was determined using the WST-1 assay kit (Roche Diagnostic $\mathrm{GmbH}$, Mannheim, Germany). Cells were incubated for 0, 6, 12,24 and $48 \mathrm{~h}$ with or without $10^{-5} \mathrm{M}$ forskolin and then harvested, fixed with $95 \%$ ethanol and digested with $0.2 \mathrm{mg} /$ $\mathrm{ml}$ RNase (Sigma). Cells were stained with propidium iodide and examined for changes in the cell cycle distribution using flow cytometry (FACS Calibur 3A, Becton Dickinson, Franklin Lakes, NJ). Statistical analysis was performed using Student's t-test, with $\mathrm{p}<0.05$ considered to be statistically significant.

Western blot analysis. K1 cells were cultured in DMEM medium supplemented with $2.5 \%$ FBS and $10^{-5} \mathrm{M}$ forskolin for 2 days. IGF- 1 or HGF were added, and cells were incubated for 0-120 min. After stimulation by IGF-1 and HGF, cells were solubilized in lysis buffer [62.5 mM Tris/HCl $(\mathrm{pH}$ 6.8), 
Table I. The effect of forskolin on K1 cell cycle was analyzed by flow cytometry.

\begin{tabular}{crrr}
\hline & G0/G1 & \multicolumn{1}{c}{$\mathrm{S}$} & \multicolumn{1}{c}{$\mathrm{G} 2 / \mathrm{M}$} \\
\hline Control & & & \\
$0 \mathrm{H}$ & $92.0 \pm 5.0$ & $3.41 \pm 1.2$ & $4.45 \pm 0.6$ \\
$6 \mathrm{H}$ & $87.1 \pm 2.5$ & $9.8 \pm 0.3$ & $3.1 \pm 0.5$ \\
$12 \mathrm{H}$ & $69.2 \pm 1.6$ & $23.7 \pm 2.8$ & $5.2 \pm 0.5$ \\
$24 \mathrm{H}$ & $78.7 \pm 5.6$ & $11.6 \pm 2.6$ & $9.7 \pm 0.8$ \\
$48 \mathrm{H}$ & $92.8 \pm 4.8$ & $2.6 \pm 0.5$ & $4.5 \pm 0.9$ \\
$10^{-5} \mathrm{M} \mathrm{Forskolin}$ & & & \\
$0 \mathrm{H}$ & $92.0 \pm 5.0$ & $3.41 \pm 1.2$ & $4.45 \pm 0.6$ \\
$6 \mathrm{H}$ & $84.2 \pm 1.7$ & $9.4 \pm 0.3$ & $6.4 \pm 0.3$ \\
$12 \mathrm{H}$ & $82.4 \pm 8.0^{\mathrm{a}}$ & $9.6 \pm 0.4$ & $7.8 \pm 0.4$ \\
$24 \mathrm{H}$ & $90.1 \pm 9.5$ & $3.5 \pm 0.8$ & $6.4 \pm 1.2$ \\
$48 \mathrm{H}$ & $96.0 \pm 3.9$ & $1.2 \pm 0.3$ & $2.8 \pm 0.7$ \\
\hline
\end{tabular}

Data are expressed as mean \pm SD percent. ${ }^{\mathrm{a}} \mathrm{p}<0.05$ vs. control.

$2 \%$ sodium dodecylsulfate, $10 \%$ glycerol, $50 \mathrm{mM}$ DTT and $0.01 \%$ bromophenol blue] and then sonicated. Protein $(30 \mu \mathrm{g})$ from the cell lysates was incubated at $95^{\circ} \mathrm{C}$ for $5 \mathrm{~min}$ and then loaded onto a $12.5 \%$ polyacrylamide gel. After separation in SDS-PAGE, proteins were transferred onto nitrocellulose membrane (Protran, Schleicher \& Schuell, NH, USA). The membrane was blocked in 5\% skim milk powder in PBS for $30 \mathrm{~min}$, washed and then immunoreacted with rabbit antip42/44 antibody (1:1000) or anti-phospho p44/42 antibody (1:1000) (Cell Signaling Technology, Beverly, MA), followed by a peroxidase-conjugated secondary anti-rabbit IgG antibody (1:2000) (Amersham Biosciences, Buckinghamshire, UK). Antigen-antibody complexes were detected by incubation with chemiluminescence reagent (Perkin Elmer Life Sciences, Boston, MA) and exposure to autoradiographic film.

\section{Results}

TSHR expression status in the thyroid cancer cell lines. Total RNA was extracted from K1, TTA1 and TT2 cells as well as one normal thyroid tissue and two papillary thyroid cancers. RT-PCR was performed to investigate TSHR expression. TSHR was not expressed in the K1, TTA1 and TTA2 thyroid cells, although TSHR was expressed in normal thyroid tissue and papillary thyroid cancer tissues (Fig. 1).

Forskolin inhibits proliferation of thyroid cancer cells. To explore the role of the cAMP pathway on thyroid cancer cell proliferation, three thyroid cancer cell lines, K1, TTA1 and TTA2, were cultured with and without the addition of forskolin $\left(0-10^{-4} \mathrm{M}\right)$. Forskolin inhibited proliferation of the $\mathrm{K} 1$ and TTA1 cells in a dose-dependent manner (Fig. 2). In the K1 cells, at $48 \mathrm{~h}$ after culture with forskolin cell proliferation was inhibited by $67.9,50$, and $30.9 \%$ in $10^{-6} \mathrm{M}, 10^{-5} \mathrm{M}$, and $10^{-4} \mathrm{M}$ forskolin, respectively $(\mathrm{p}<0.05)$. The proliferation of TTA 1 and TTA2 cells were also inhibited; however,

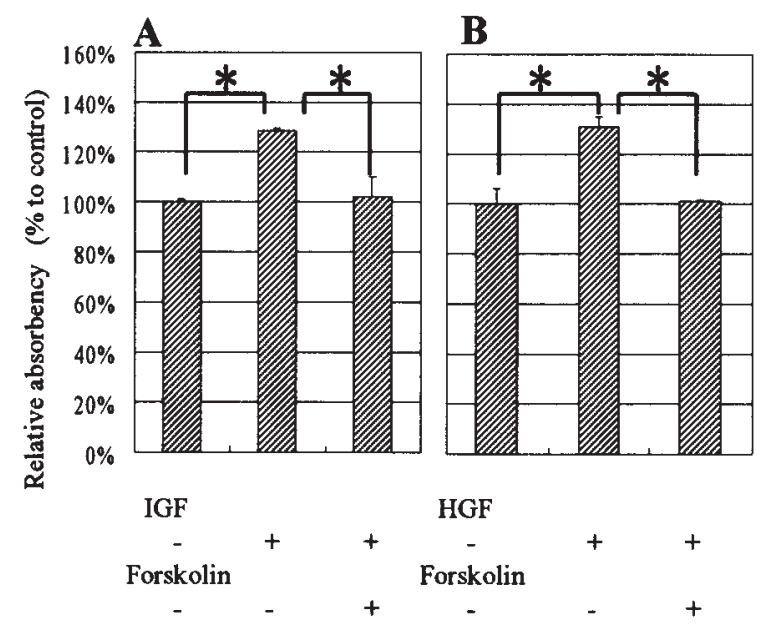

Figure 3. IGF and HGF induced cell growth in $\mathrm{K} 1$ cultures. $\mathrm{K} 1$ cells were incubated with IGF (1 ng/ml) (A) and HGF (10 ng/ml) (B) in the absence or presence of $10^{-5} \mathrm{M}$ forskolin for $48 \mathrm{~h}$. After incubation, a WST-1 cell proliferation assay was performed. All absorbencies are expressed as a percentage of the untreated control cultures. Data are expressed as the mean \pm SD percent cell growth vs. control. ${ }^{*} \mathrm{p}<0.05$ vs. control.

statistically significant differences were seen only at a high concentration of forskolin. A dose-dependent inhibition of cell proliferation was observed in $\mathrm{K} 1$ cells. These data suggest that activation of the cAMP pathway by forskolin suppresses cell proliferation in thyroid cancer cell lines. K1 cells were selected for further studies.

Table I shows the effect of forskolin on cell cycle. K1 cells were cultured in serum-free medium and then stimulated by FBS. Forskolin significantly induced growth arrest at the G0/G1 phase in $\mathrm{K} 1$ cells.

Effects of growth factors on K1 cell proliferation. We further investigated the effects of growth factors that stimulate signal transduction pathways via receptor tyrosine kinases on thyroid cancer cell growth. The effects of IGF-1 and HGF on K1 cells were analyzed by a cell growth assay. IGF-1 and HGF stimulated K1 cell proliferation at 128.3 and $131.7 \%$, respectively, compared with controls (control versus IGF-1 or HGF: p<0.05) (Fig. 3). K1 cells were incubated with $10^{-5} \mathrm{M}$ forskolin, and IGF-1 or HGF were added. The cell growth was controlled to the same degree of proliferation as control. Interestingly, the cell proliferation induced by IGF-1 and HGF was suppressed with the forskolin treatment.

Effects of forskolin on MAPK signaling pathway in K1 cells. Since IGF-1 and HGF stimulated K1 cells experienced growth inhibition with forskolin, we next decided to examine the expression of signal transducers. We examined the expression of MAPK after forskolin treatment. After a 12-h treatment with or without forskolin, the K1 cells were stimulated with IGF-1 and HGF. Western blotting revealed that IGF-1 stimulation with $10^{-5} \mathrm{M}$ forskolin induced a remarkable reduction in the levels of activated MAPK (Fig. 4). Similar results were obtained when forskolin-treated K1 cells were stimulated with HGF. However, the phosphorylation of MAPK did not change with HGF stimulation alone. Forskolin inhibited 


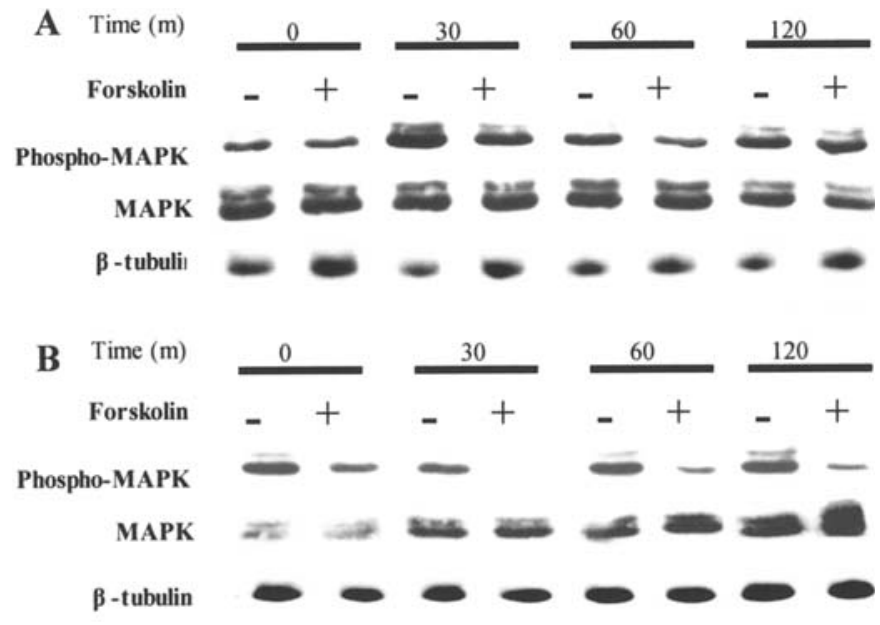

Figure 4. Forskolin-induced changes in phosphorylation of mitogenactivated protein kinase (MAPK) and the effects of IGF-1 and HGF on K1 cells. $\mathrm{K} 1$ cells were incubated with or without forskolin $\left(10^{-5} \mathrm{M}\right)$ for 2 days and then treated with IGF-1 and HGF. Between 0 and 120 min, the levels of phospho-MAPK were examined by Western blotting. (A) K1 cells were treated with $5 \mathrm{ng} / \mathrm{ml} \mathrm{IGF.} \mathrm{Phospho-MAPKs} \mathrm{are} \mathrm{seen} \mathrm{in} \mathrm{the} \mathrm{absence} \mathrm{(-)} \mathrm{but}$ reduced in the presence (+) of forskolin. (B) K1 cell were treated with $10 \mathrm{ng} /$ $\mathrm{ml}$ HGF. Phospho-MAPKs are seen in the absence (-) but not at all or reduced in the presence $(+)$ of forskolin. B-tubulin was used as a control.

growth factor induced cell proliferation via phosphorylation of the MAPK signaling pathway.

\section{Discussion}

To explore the role of the cAMP-mediated signaling pathway on the proliferation of thyroid cancers, we examined the effects of forskolin on the cell growth of three human thyroid cancer cell lines. We used K1, TTA1 and TT2 cells, which were derived from one papillary thyroid cancer and two anaplastic thyroid cancers, respectively. Generally, it is difficult to establish a cell line from a well-differentiated thyroid cancer, and the $\mathrm{K} 1$ is a precious cell line of the papillary thyroid cancer origin. The mRNA of the TSHR was not expressed in K1 cells or in TTA1 and TTA2 cells, although TSHRs are reported to be expressed in most clinical papillary thyroid cancers (18). Differentiated thyroid cancer respond to TSH stimulation by activating the cAMP cascade that promotes cell growth (19). In contrast, the expression of the TSHR is markedly decreased in poorly differentiated thyroid cancer $(19,20)$. TSHR expression represents a degree of dedifferentiation of the thyroid cancer. The K1 cells might, thus, be dedifferentiated from the original papillary thyroid cancer from which they were derived.

In this study, we demonstrated that the activation of adenylate cyclase induced by forskolin suppresses cell proliferation, especially of $\mathrm{K} 1$ cells, in a dose-dependent manner and induced growth arrest at the G0/G1 phase of the cell cycle. Our data is supported by several studies on the effects of cAMP on thyroid cancer cell growth $(4,21,22)$. It was also reported that the proliferation of thyroid cancer cells with re-expressed TSH receptors was inhibited by TSH (21). These data suggest that the proliferation of thyroid cancer cells might be controlled by the cAMP-mediated signaling pathway of TSH stimulation.
Normal thyroid follicular cells require cAMP to proliferate, and constitutive activation of the cAMP pathway induces thyroid hyperplasia. Thyroid nodules in patient with Graves' disease, who have TSHR-stimulating immunoglobulins, are common and raise concern about coexistent thyroid malignancy. Graves' disease, occasionally coexists with small incidental thyroid cancers $(23,24)$. However, a recent study has also reported that the prognosis of small papillary thyroid cancer is more favorable in patients with concomitant Graves' disease than in patients with thyroid cancer alone (24). The somatic mutations of the TSHR which activate the cAMP cascade were previously reported in autonomous functioning thyroid nodules or adenomas, as in Plummers' disease $(25,26)$. Most papillary thyroid cancers are nonfunctioning, and TSHR mutations have not yet been detected (27). TSH suppression with thyroid hormone is common and established in the management of thyroid cancer (28). On the other hand, there is little evidence on TSH suppression therapy, especially on low risk grade groups in papillary thyroid cancers (29).

Another important finding of our study is the competitive interaction between the MAPK-mediated signaling pathway of growth factors and the TSH signal pathway. IGF-1 and HGF significantly promoted the proliferation of K1 cells, which was associated with the phosphorylation of MAPK. Forskolin treatment suppressed the IGF-1-induced cell proliferation and reduced the levels of activated MAPK. Although TSH plays a major role in regulation of thyroid cell proliferation, neoplastic thyroid cell growth can be affected by growth factors such as epidermal growth factor, insulinlike growth factor, basic fibroblast growth factor, plateletderived growth factor and transforming growth factor- $\alpha$, and by activated oncogenes including RET, BRAF, and the $R A S$ family (12-14). To our knowledge, this is the first study linking the cAMP signaling pathway to MAPK signal transduction in human thyroid cancer cells. A TSH-independent mitogenic cascade might remain active in thyroid cancer, and might be retained; therefore, our results could have interesting clinical implications in light of the current anticancer use of MAPK inhibitors. However, the molecular mechanism by which cAMP activation reduces the activation of MAPK should be studied further.

In conclusion, we demonstrated that forskolin notably suppressed cell growth, involved in G1 arrest in K1 thyroid cancer cells and we found forskolin decreased the activation of the MAPK protein, especially in K1 cells derived from papillary thyroid cancer, despite the fact that the expression of the TSHR is lost in $\mathrm{K} 1$ cells.

\section{References}

1. Roger P, Taton M, Van Sande J and Dumont JE: Mitogenic effects of thyrotropin and adenosine $3^{\prime}, 5^{\prime}$-monophosphate in differentiated normal human thyroid cells in vitro. J Clin Endocrinol Metab 66: 1158-1165, 1988.

2. Kraiem Z, Sadeh O, Yosef M and Aharon A: Mutual antagonistic interactions between the thyrotropin (adenosine 3',5'-monophosphate) and protein kinase C/epidermal growth factor (tyrosine kinase) pathways in cell proliferation and differentiation of cultured human thyroid follicles. Endocrinology 136: 585$590,1995$.

3. Seamon KB, Padgett W and Daly JW: Forskolin: unique diterpene activator of adenylate cyclase in membranes and in intact cells. Proc Natl Acid Sci USA 78: 3363-3367, 1981. 
4. Ohta K, Pang XP, Berg L and Hershman JM: Growth inhibition of new human thyroid carcinoma cell lines by activation of adenylate cyclase through the beta-adrenergic receptor. J Clin Endocrinol Metab 82: 2633-2639, 1997.

5. Wynford-Thomas D, Sringer BM and Williams ED: Desensitisation of rat thyroid to the growth-stimulating action of TSH during prolonged goitrogen administration. Persistence of refractoriness following withdrawal of stimulation. Acta Endocrinol 101: 562-569, 1982.

6. Smith P, Williams ED and Wynford-Thomas D: In vitro demonstration of a TSH-specific growth desensitising mechanism in rat thyroid epithelium. Mol Cell Endocrinol 51: 51-58, 1987.

7. Siperstein AE, Zeng QH, Gum ET, Levin KE and Clark OH: Adenylate cyclase activity as a predictor of thyroid tumor aggressiveness. World J Surg 12: 528-533, 1988.

8. Mazzaferri EL and Young RL: Papillary thyroid carcinoma: a 10 year follow-up report of the impact of therapy in 576 patients. Am J Med 70: 511-518, 1981.

9. Iacovelli L, Capobianco L, Salvatore L, Sallese M, D'Ancona G and De Blasi A: Thyrotropin activates mitogen-activated protein kinase pathway in FRTL-5 by a cAMP-dependent protein kinase A-independent mechanism. Mol Pharmacol 60: 924-933, 2001.

10. Lamy F, Wilkin F, Baptist M, Posada J, Roger PP and Dumont JE: Phosphorylation of mitogen-activated protein kinases is involved in the epidermal growth factor and phorbol ester, but not in the thyrotropin/cAMP, thyroid mitogenic pathway. J Biol Chem 268: 8398-8401, 1993.

11. Duh QY and Grossman RF: Thyroid growth factors, signal transduction pathways, and oncogenes. Surg Clin North Am 75: 421-437, 1995.

12. Fusco A, Viglietto $G$ and Santoro M: A new mechanism of BRAF activation in human thyroid papillary carcinomas. J Clin Invest 115: 20-23, 2005.

13. Mansour SJ, Matten WT, Hermann AS, Candia JM, Rong S, Fukasawa K, Vande Woude GF and Ahn NG: Transformation of mammalian cells by constitutively active MAP kinase kinase. Science 265: 966-970, 1994.

14. Ringel MD, Hardy E, Bernet VJ, Burch HB, Schuppert F, Burman KD and Saji M: Metastin receptor is overexpressed in papillary thyroid cancer and activates MAP kinase in thyroid cancer cells. J Clin Endocrinol Metab 87: 2399, 2002.

15. Wyllie FS, Lemoine NR, Barton CM, Dawson T, Bond $\mathrm{J}$ and Wynford-Thomas D: Direct growth stimulation of normal human epithelial cells by mutant p53. Mol Carcinog 7: 83-88, 1993.

16. Yoshida A, Asaga T, Masuzawa $\mathrm{C}$ and Kawahara S: Alternation of tumorigenicity in undifferentiated thyroid carcinoma cells by introduction of normal chromosome 11. J Surg Oncol 55: 170-174, 1994.
17. Major BJ, Cures A and Frauman AG: The full length and splice variant thyrotropin receptor is expressed exclusively in skeletal muscle of extraocular origin: a link to the pathogenesis of Graves' ophthalmopathy. Biochem Biophys Res Commun 230: 493-496, 1997.

18. Brabant G, Maenhaut C, Kohrle J, Scheumann G, Dralle H, Hoang-Vu C, Hesch RD, von zur Muhlen A, Vassart G and Dumont JE: Human thyrotropin receptor gene: expression in thyroid tumors and correlation markers of thyroid differentiation and dedifferentiation. Mol Cell Endocrinol 82: R7-12, 1991.

19. Carayon P, Thomas-Morvan C, Castanas E and Tubiana M: Human thyroid cancer: membrane thyrotropin binding and adenylate cyclase activity. J Endocrinol Metab 57: 140-147, 1980 .

20. Ohta K, Endo T and Onaya T: The mRNA levels of thyrotropin receptor, thyroglobulin and thyroid peroxidase in neoplastic human thyroid tissues. Biochem Biophy Res Commun 174: 1148-1153, 1991.

21. Derwahl M, Kuemmel M, Goretzki P, Schatz H and Broecker M: Expression of the human TSH receptor in a human thyroid carcinoma cell line that lacks an endogeneous TSH receptor: growth inhibition by cAMP. Biochem Biophys Res Commun 191: 1131-1138, 1993.

22. Hishinuma A, Yamanaka T, Kasai K, So S, Bamba N and Shimoda SI: Growth regulation of the human papillary thyroid cancer cell line by protein tyrosine kinase and cAMP-dependent protein kinase. Endocrinol J 41: 399-407, 1994.

23. Cantalamessa L, Baldini M, Orsatti A, Meroni L, Amodei V and Castagnone D: Thyroid nodules in Graves' disease and the risk of thyroid carcinoma. Arch Intern Med 159: 1705-1706, 1999.

24. Kikuchi S and Noguchi S: Prognosis of small thyroid cancer in patients with Graves' disease. Br J Surg 93: 434-439, 2006.

25. Kosugi S, Hai N, Okamoto H, Sugawa H and Mori T: A novel activating mutation in the thyrotropin receptor gene in an autonomously functioning thyroid nodule developed by a Japanese patient. Eur J Endocrinol 143: 471-477, 2000.

26. Vanvooren V, Uchino S, Duprez L, Costa MJ, Vandekerckhove J, Parma J, Vassart G, Dumont JE, Van Sande J and Noguchi S: Oncogenic mutations in the thyrotropin receptor of autonomously functioning thyroid nodules in the Japanese population. Eur J Endocrinol 147: 287-291, 2002.

27. Cetani F, Tonacchera M, Pinchera A, Barsacchi R, Basolo F, Miccoli P and Pacini F: Genetic analysis of the TSH receptor gene in differentiated human thyroid carcinomas. J Endocrinol Invest 22: 273-278, 1999.

28. Clark OH: TSH suppression in the management of thyroid nodules and thyroid cancer. World J Surg 5: 39-47, 1981.

29. Biondi B, Filetti S and Schlumberger M: Thyroid-hormone therapy and thyroid cancer: a reassessment. Nat Clin Pract Endcrinol Metab 1: 32-34, 2005. 